\title{
MODE I INTERLAMINAR FRACTURE OF CARBON/EPOXY MULTIDIRECTIONAL LAMINATES
}

\author{
A. B. PEREIRA ${ }^{1}$, A. B. DE MORAIS ${ }^{1}$, M. F. S. F. DE MOURA ${ }^{2}$ and A. G. MAGALHÃES ${ }^{3}$ \\ ${ }^{1}$ University of Aveiro, Department of Mechanical Engineering, Aveiro, Portugal \\ ${ }^{2}$ University of Porto, Faculty of Engineering, Department of Mechanical Engineering, Porto, Portugal \\ ${ }^{3}$ Institute of Engineering, Department of Mechanical Engineering, Porto, Portugal
}

\begin{abstract}
An experimental study was conducted on the mode I interlaminar fracture of carbon/epoxy multidirectional specimens with starter delaminations in $0 / 0$ and $0 / \theta$ interfaces. The specimens selected for Double Cantilever Beam (DCB) tests had $\left[\left(0_{2} / 90\right)_{6} / 0_{2} / /\left(0_{2} / 90\right)_{6} / 0_{2}\right]$ and $\left[\left(0_{2} / 90\right)_{6} / 0_{2} / / \theta /\left(0_{2} / 90\right)_{6} / 0_{2}\right]$ stacking sequences, where // denotes the position of the starter delamination and $\theta=22.5$ to 90 degrees. The incorporation of the thick symmetric $\left[\left(0_{2} / 90\right)_{6} / 0_{2}\right]$ block of 20 plies aimed at minimising elastic couplings related problems, such as non-uniform width-wise distributions of the strain energy release rate $G_{\mathrm{I}}$, spurious modes and effects of residual stresses. This was verified in preliminary three-dimensional (3D) Finite Element (FE) analyses, which also showed the applicability of the Corrected Beam Theory data reduction scheme. The DCB specimens were tested according to the procedures defined in the ISO 15024:2001 standard for unidirectionally reinforced specimens. In the tests, intraply damage occurred in the $\theta$-oriented ply soon after initiation from the starter crack, as it is commonly observed in multidirectional specimens. For $\theta=22.5$ and 45 degrees, a second crack propagated close to a neighbouring interface, while for $\theta=67.5$ and 90 degrees the starter crack ran inside the $\theta$-oriented ply and proceeded in a wavy propagation trajectory. This resulted in extensive fibre bridging and pronounced $R$-curves with artificially high final values of the critical strain energy release rate, $G_{I c}$. Therefore, only $G_{\mathrm{Ic}}$ values of initiation could be considered true interlaminar properties. Moreover, it was found that they were fairly independent of the ply angle $\theta$. An additional FE analysis of the interlaminar stresses ahead of the crack tip was performed to interpret the delaminating interface effect on $G_{\text {Ic }}$ values. The results indicated the existence of an interface independent fracture toughness, $K_{\mathrm{Ic}}$, probably resin controlled, thus reinforcing the idea that the measured initiation $G_{\mathrm{Ic}}$ were pure interlaminar properties.
\end{abstract}

\section{INTRODUCTION}

Delamination is a common damage mode of high performance laminated composites which can be particularly detrimental for structural behaviour. The characterisation of delamination resistance has been the subject of many studies, especially under mode I loading. Those efforts lead to the standardisation of the Double Cantilever Beam (DCB) test (figure 1) for measuring the critical strain energy release rate, $G_{\mathrm{I} c}$, of unidirectional (UD) $[0]_{\mathrm{n}}$ laminates [1]. In fact, UD specimens are quite convenient for testing purposes, due to the high stiffness and ability to maintain self-similar crack propagation. However, the majority of applications involve multidirectional (MD) laminates and it is observed that delaminations usually occur between layers of different orientations. It is therefore essential to obtain $G_{I c}$ values of MD specimens for the development of accurate fracture criteria.

Several studies were already conducted on the mode I fracture of MD laminates with delaminations in $\theta / \theta, \theta /-\theta$ and $0 / 90$ interfaces [2-9]. The major problem is the development of intraply damage, often associated with extensive fibre bridging and non-linearity. Those phenomena are responsible for steep $R$-curves, with final $G_{I c}$ values 3 to 4 times higher than those of UD specimens. Obviously, such $G_{\mathrm{Ic}}$ values are not valid measures of delamination resistance. 


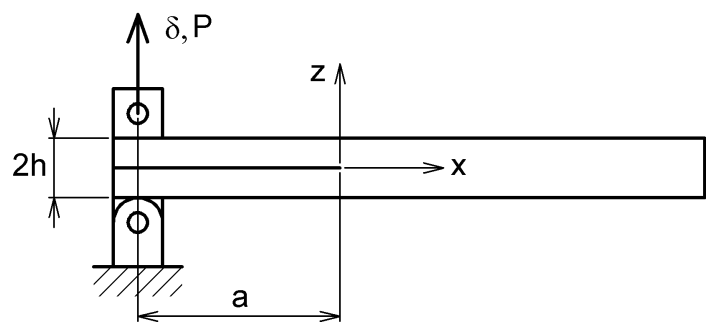

Figure 1: The DCB specimen.

On the other hand, Chai [2] observed several areas of pure interlaminar propagation along 0/90, $0 / 45$ and $45 /-45$ interfaces of thick specimens and obtained interface independent $G_{\mathrm{I} c}$ values. This paper describes an experimental study on the mode I fracture of thick carbon/epoxy MD specimens with starter delaminations in $0 / \theta$ interfaces.

\section{ANALYSIS OF MULTIDIRECTIONAL DCB SPECIMENS}

MD laminates usually present elastic couplings which can be the source of significant errors in $G_{\text {Ic }}$ measurements $[5,10]$. For example, bending-bending couplings may generate highly curved thumbnail shaped delamination fronts, while membrane-bending couplings can induce significant contributions of thermal residual stresses to the measured $G_{\mathrm{I} c}$. Therefore, selected specimens must be analysed for possible elastic couplings associated problems. The present study focussed on specimens with $0 / \theta$ delaminating interfaces and is part of a research project which also involves mode II testing. Previous FE analyses of End-Notched Flexure (ENF) specimens [11] lead to the selection of $\left[\left(0_{2} / 90\right)_{6} / 0_{2} / /\left(0_{2} / 90\right)_{6} / 0_{2}\right]$ and $\left[\left(0_{2} / 90\right)_{6} / 0_{2} / / \theta /\left(0_{2} / 90\right)_{6} / 0_{2}\right]$ stacking sequences, where // denotes the position of the starter delamination and $\theta=22.5$ to 90 degrees. The specimens are hereafter designated by the delaminating interface i.e. $0 / 0$ and $0 / \theta$. The incorporation of thick symmetric $\left[\left(0_{2} / 90\right)_{6} / 0_{2}\right]$ blocks of 20 plies minimised the elastic couplings related problems mentioned above and effectively avoided large displacements, plastic deformations and intraply damage. These features are also favourable for DCB tests, as the following analysis confirms.

The specimen dimensions were width $b=20 \mathrm{~mm}$, crack lengths $a$ from 70 to $160 \mathrm{~mm}$ (figure 1), total length $200 \mathrm{~mm}$, and thickness $2 h$ from 6.0 to $6.15 \mathrm{~mm}$ as a result of the $t=0.15 \mathrm{~mm}$ ply thickness. FE models were constructed with the commercial code ABAQUS ${ }^{\circledR}$ using 3D 8-node brick elements. Figure 2 shows a typical FE mesh, which combined refinement near the crack tip with the use of layered elements, in order to achieve accurate results without excessive computational cost. The virtual crack closure technique (VCCT) [12] was employed to compute the strain energy release rate components $G_{\mathrm{I}}, G_{\mathrm{II}}$ and $G_{\mathrm{III}}$. For cracks between differently oriented plies, it was shown that mode partitioning is somewhat dependent on the crack closure increment $\Delta a$, although the total strain energy release rate $G=G_{\mathrm{I}}+G_{\mathrm{II}}+G_{\mathrm{III}}$ is well defined [13]. However, if $\Delta a$ is viewed as a characteristic damage zone length of the order of the ply thickness $t$, mode partitioning becomes practically stable [13]. The ply thermoelastic properties of the carbon/epoxy material used in this study were $E_{1}=130 \mathrm{GPa}, E_{2}=8.2 \mathrm{GPa}, v_{12}=0.27, G_{12}=4.1 \mathrm{GPa}, v_{23}=0.41$, $\alpha_{1}=-0.1 \cdot 10^{-6} /{ }^{\circ} \mathrm{C}$ and $\alpha_{2}=26 \cdot 10^{-6} /{ }^{\circ} \mathrm{C}$.

Figure 3 shows the distributions along the specimen width of $G_{\text {I }}$ normalised by the width-wise average. They can be considered fairly uniform [5,10], with only a small degree of asymmetry for $0 / 45$ specimens. On the other hand, mode-mixity analysis showed a clear prevalence of mode I, as the width-wise average $G_{\mathrm{I}} / G$ ratios were above $97.5 \%$ [14]. 


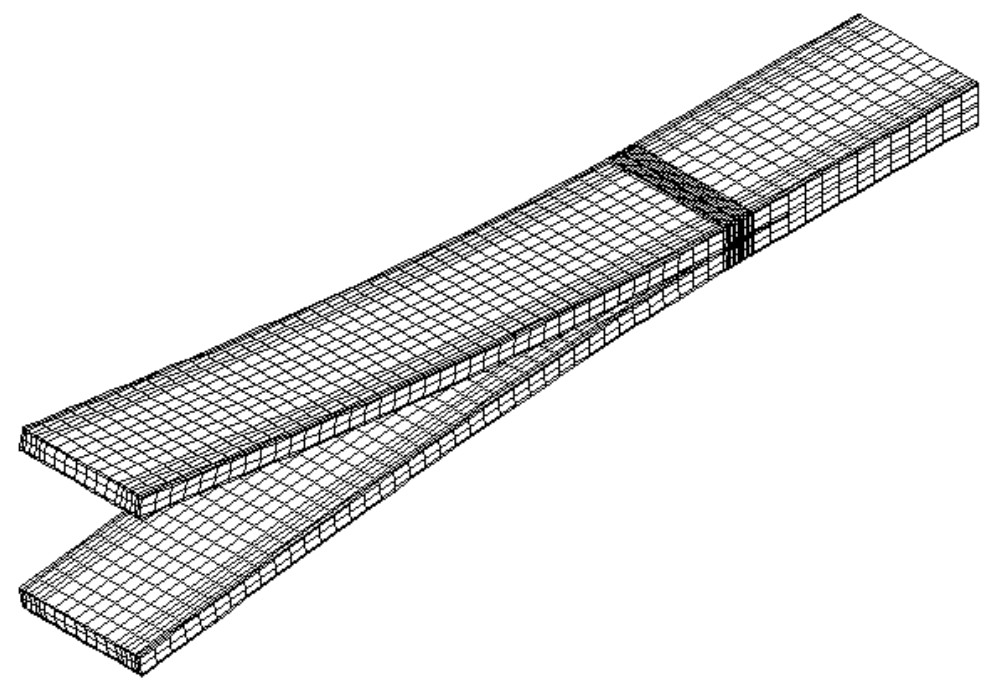

Figure 2: Typical FE mesh.

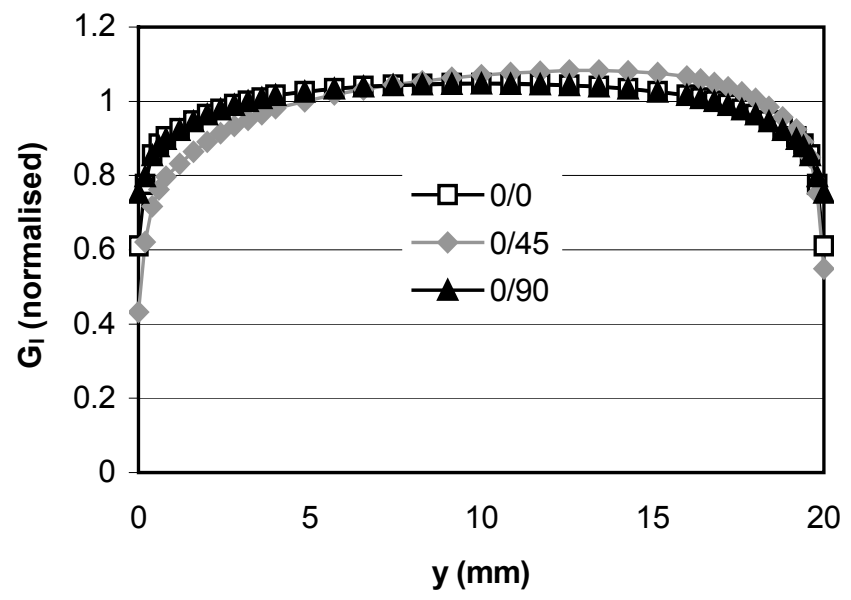

Figure 3: Width-wise distributions of $G_{\mathrm{I}}$ normalised by the average value.

In actual tests, the load $P$ and displacements $\delta$ recorded for specified crack positions $a$ (figure 1) are usually processed with Corrected Beam Theory (CBT) [1]

$$
G_{\text {I }}=\frac{3 P \delta}{2 b(a+|\Delta|)} \frac{F}{N},
$$

where $\Delta$ is a correction for crack tip rotation and deflection, $F$ is a correction factor for large displacements and $N$ is a correction factor for the stiffening caused by the metal blocks. In order to evaluate the suitability of CBT for $0 / \theta$ specimens, $P-\delta$ - $a$ data were obtained from FE models with $a=70$ to $160 \mathrm{~mm}$. As shown in table 1, eqn (1) was in good agreement with the width-wise average $G_{\mathrm{I}}$ computed using VCCT. 
Table 1: Errors (\%) of eqn (1) relative to the width-wise average $G_{\mathrm{I}}$ obtained from VCCT.

\begin{tabular}{ccccc}
\hline & $\mathrm{a}(\mathrm{mm})$ & & & \\
\cline { 2 - 5 } Specimen & 70 & 100 & 130 & 160 \\
\hline $0 / 0$ & 1.65 & 1.65 & 1.68 & 1.68 \\
$0 / 45$ & 3.35 & 3.35 & 3.36 & 3.39 \\
$0 / 90$ & 3.94 & 3.92 & 3.95 & 3.97 \\
\hline
\end{tabular}

The effects of residual stresses on $G_{\text {Ic }}$ measurements were assessed with the above FE models by performing a preliminary $100{ }^{\circ} \mathrm{C}$ temperature decrease loading step. The results showed they were already lower than $1.2 \%$ for the small width-wise average $G_{\mathrm{I}} \approx 100 \mathrm{~J} / \mathrm{m}^{2}$ assumed at this stage [14]. We could therefore conclude that the proposed specimens were adequate for DCB tests.

\section{EXPERIMENTAL}

The laminated plates were manufactured from a unidirectional high strength carbon fibre/epoxy prepreg (HS 160 REM from Texipreg) by hot plate pressing. A $15 \mu \mathrm{m}$ thick PTFE film was used to generate the starter crack The specimens were cut from the plates with the nominal dimensions of the FE models. Precrack lengths were either 70 or $100 \mathrm{~mm}$. Machined Al alloy blocks were glued to the specimens for load transmission. One of the specimen edges was coated with typewriter correction fluid and several marks were made to facilitate the monitoring of crack position.

Tests were carried out in a Shimadzu machine at $1 \mathrm{~mm} / \mathrm{min}$ crosshead speed. Following the procedures of ISO 15024:2001, a pre-cracking cycle was performed, which consisted in propagating the crack from the insert by about $3 \mathrm{~mm}$. Initiation values from the insert were then recorded. Further measurements were made in an additional loading cycle, where the crack was allowed to propagate by about $50 \mathrm{~mm}$. However, in contrast with the work by Chai [2], intraply damage occurred soon after initiation from the film. In 0/22.5 and 0/45 specimens, a second crack propagated close to the neighbouring $0 / 22.5$ and $0 / 45$ starter interfaces, respectively (figure 4 ). As to $0 / 67.5$ and $0 / 90$ specimens, the starter crack ran inside the $\theta$-oriented ply and proceeded in a wavy propagation trajectory. Naturally, this gave rise to extensive fibre bridging (figure 4) and to pronounced R-curves [14]. In these circumstances, it is clear that only the initiation $G_{\text {Ic }}$ from the film can be considered interlaminar properties. Owing to difficulties in defining the exact instant of crack initiation, the non-linearity (NL) and the $5 \%$ offset or maximum load $(5 / \mathrm{M})$ criteria were used [1]. As shown in figure 5, they seemed to be fairly independent of the ply angle $\theta$. Although interface independent $G_{I c}$ values were also reported by Chai [2], the analysis below was conducted to assist the interpretation of experimental results.
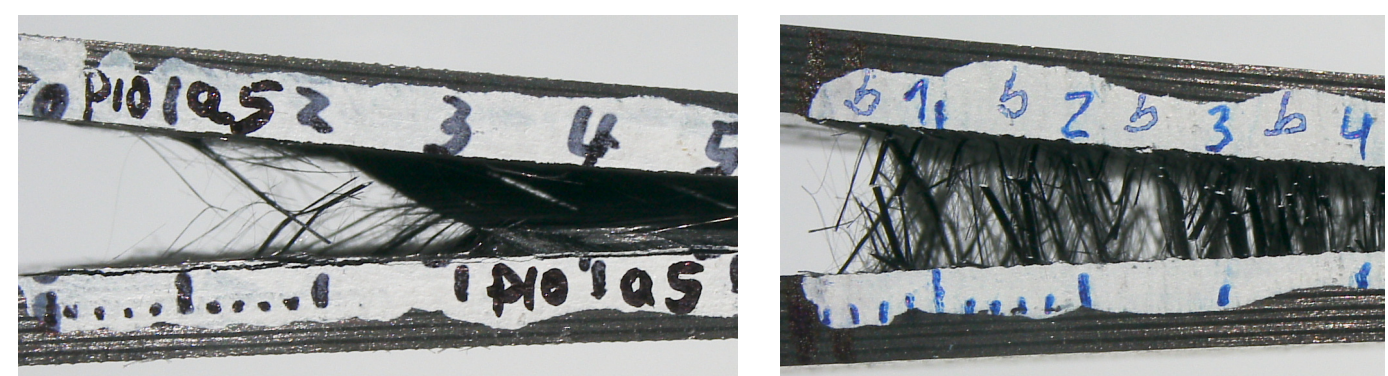

Figure 4: Pictures of 0/45 (left) and 0/90 specimens (right). 


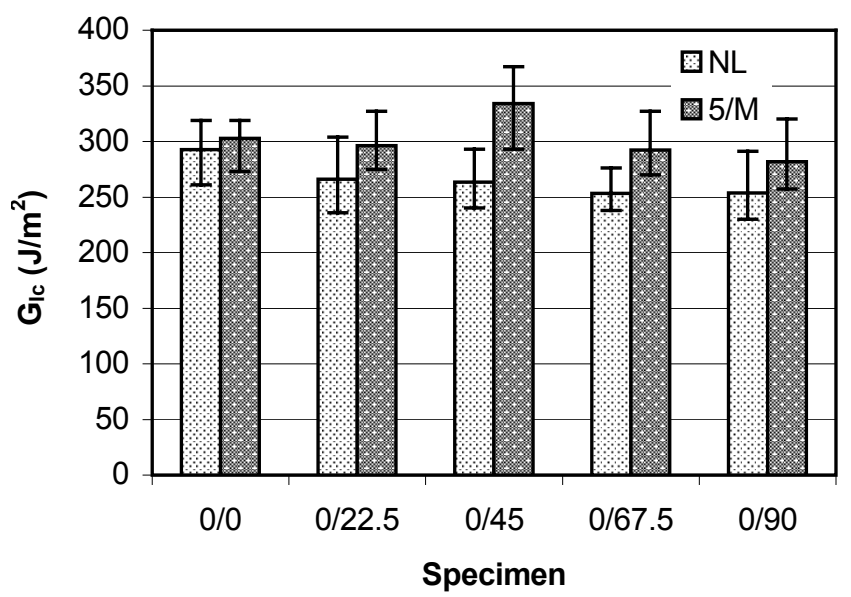

Figure 5: Average and scatter range of initiation $G_{\mathrm{Ic}}$ obtained with the non-linearity (NL) and $5 \%$ off-set or maximum load (5/M) criteria.

\section{INTERPRETATION OF THE INTERFACE EFFECT ON $G_{\text {Ic }}$}

The delamination resistance of laminated composites has been usually characterised by critical strain energy release rates, as they can be measured in fracture tests. Furthermore, the oscillatory nature of the stress field near delaminations between plies with different orientations demands "characteristic length stress intensity factors", which are quite difficult to evaluate [13]. However, the above analysis showed that crack propagation in the DCB specimens was largely mode I dominated. Therefore, the classical Fracture Mechanics [15] relations for pure mode I problems were assumed to give good approximations. It is easy to show [14] that

$$
\frac{G_{\mathrm{Ic}}(0 / \theta)}{G_{\mathrm{I} c}(0 / 0)}=\lambda_{\mathrm{I}} \frac{K_{\mathrm{Ic}}^{2}(0 / \theta)}{K_{\mathrm{Ic}}^{2}(0 / 0)},
$$

where

$$
\lambda_{\mathrm{I}}=\left[\frac{G_{\mathrm{I}}}{K_{\mathrm{I}}^{2}}\right]\left(l_{c}, 0 / \theta\right) /\left[\frac{G_{\mathrm{I}}}{K_{\mathrm{I}}^{2}}\right]\left(l_{c}, 0 / 0\right) .
$$

On the other hand, $K_{\mathrm{I}}\left(l_{c}\right)$ can be expressed as a function of the $l_{c}$-averaged interlaminar stress,

so that

$$
K_{\mathrm{I}}\left(l_{c}\right) \approx \sqrt{\frac{\pi l_{c}}{2}} \bar{\sigma}_{z}\left(l_{c}\right),
$$

$$
\lambda_{\mathrm{I}} \approx\left[\frac{G_{\mathrm{I}}}{\bar{\sigma}_{z}^{2}}\right]\left(l_{c}, 0 / \theta\right) /\left[\frac{G_{\mathrm{I}}}{\bar{\sigma}_{z}^{2}}\right]\left(l_{c}, 0 / 0\right) .
$$

This ratio should not be very sensitive to the exact $l_{c}$ values of the order of the ply thickness $t$, if the above assumptions are valid. In order to obtain accurate $\lambda_{\mathrm{I}}$ ratios, very fine local meshing was employed i.e. the size of the elements near the crack tip was as small as $t / 10$ in convergence studies. As shown in figure $6, \lambda_{\mathrm{I}}$ ratios were practically $l_{c}$-independent and very close to 1 . 


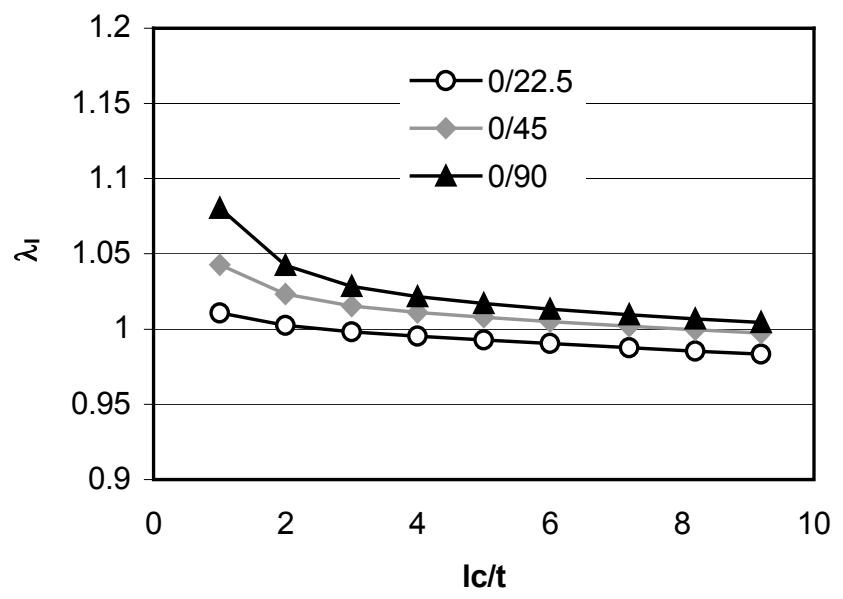

Figure 6: Predicted $\lambda_{\mathrm{I}}$ ratio (5) versus the characteristic length-to-ply thickness $\left(l_{c} / t\right)$ ratio.

Since experimental initiation $G_{\mathrm{I} c}$ values were nearly identical for the tested specimens, equation (2) suggests the existence of an interface independent fracture toughness $K_{\mathrm{I}}$, probably resin controlled. This reinforces the idea that measured initiation $G_{\text {Ic }}$ values were pure interlaminar properties.

\section{AKNOWLEDGEMENTS}

The authors thank the support of the Portuguese Foundation for Science and Technology (FCT, research project POCTI/EME/38731/2001, FEDER European Union fund).

\section{REFERENCES}

1. ISO 15024:2001. Fibre-reinforced plastic composites - Determination of mode I interlaminar fracture toughness, $\mathrm{G}_{\mathrm{Ic}}$, for unidirectionally reinforced materials.

2. Chai H. Composites 1984; 15: 277-290.

3. Laksimi A, Benzeggagh ML, Jing G, Hecini M, Roelandt JM. Compos Sci Technol, 41:147164, 1991.

4. Robinson P, Song DQ. J Compos Mater, 26:1554-1577, 1992.

5. Polaha JJ, Davidson BD, Hudson RC, Pieracci A. J Reinf Plast Compos, 15:141-173, 1996.

6. Choi NS, Kinloch AJ, Williams JG. J Compos Mater 33: 73-100, 1999.

7. Benyahia AA, Benzeggagh ML, Gong XL. Compos Sci Technol, 60:597-604, 2000.

8. Rhee KY, Koh SK, Lee JH. Polym Compos 21:155-164, 2000.

9. de Morais AB, de Moura MF, Marques AT, de Castro PT. Compos Sci Technol, 62:679-686, 2002.

10. Davidson BD, Krüger R, König M. Engng Fract Mech; 55:557-569, 1996.

11. Pereira AB, de Morais AB, Marques AT, de Castro PT. Mode II interlaminar fracture of carbon/epoxy multidirectional laminates. To be published in Compos Sci Technol.

12. Shivakumar KN, Tan PW, Newman JC. Int J Fract 1988;36:R43-R50.

13. Chow WT, Atluri SN. Composites 1997; 28B: 375-384.

14. Pereira AB, de Morais AB. Mode I interlaminar fracture of carbon/epoxy multidirectional laminates. To be published in Compos Sci Technol.

15. Kaninnen MF, Popelar CH. Advanced Fracture Mechanics. Oxford University Press, 1985. 